\title{
Reduced Graphene Oxide Aerogel inside Melamine Sponge as an Electrocatalyst for the Oxygen Reduction Reaction
}

\author{
Roman A. Manzhos ${ }^{1}\left(\mathbb{D}\right.$, Sergey A. Baskakov ${ }^{1}$, Evgeny N. Kabachkov ${ }^{1,2}{ }^{(D}$, Vitaly I. Korepanov ${ }^{3}{ }^{\mathbb{D}}$, \\ Nadezhda N. Dremova ${ }^{1}$, Yulia V. Baskakova ${ }^{1}$, Alexander G. Krivenko ${ }^{1}$, Yury M. Shulga ${ }^{1,4}$ \\ and Gennady L. Gutsev ${ }^{5, *}$
}

1 Institute of Problems of Chemical Physics, Russian Academy of Sciences, 142432 Chernogolovka, Russia; rmanzhos@yandex.ru (R.A.M.); baskakov@icp.ac.ru (S.A.B.); en.kabachkov@gmail.com (E.N.K.); dremova@icp.ac.ru (N.N.D.); ybaskakova@yandex.ru (Y.V.B.); krivenko@icp.ac.ru (A.G.K.); yshulga@gmail.com (Y.M.S.)

2 Chernogolovka Scientific Center, Russian Academy of Sciences, 142432 Chernogolovka, Russia

3 Institute of Microelectronics Technology and High Purity Materials, Russian Academy of Sciences, 142432 Chernogolovka, Russia; korepanov@iptm.ru

4 Institute of New Materials and Nanotechnologies, National University of Science and Technology MISIS, Leninsky pr. 4, 119049 Moscow, Russia

5 Department of Physics, Florida A\&M University, Tallahassee, FL 32307, USA

* Correspondence: gennady.gutsev@famu.edu

Citation: Manzhos, R.A.;

Baskakov, S.A.; Kabachkov, E.N.; Korepanov, V.I.; Dremova, N.N.; Baskakova, Y.V.; Krivenko, A.G.;

Shulga, Y.M.; Gutsev, G.L. Reduced Graphene Oxide Aerogel inside

Melamine Sponge as an

Electrocatalyst for the Oxygen

Reduction Reaction. Materials 2021,

14, 322. https://doi.org/10.3390/

ma14020322

Received: 18 December 2020

Accepted: 6 January 2021

Published: 9 January 2021

Publisher's Note: MDPI stays neutral with regard to jurisdictional clai$\mathrm{ms}$ in published maps and institutional affiliations.

Copyright: $(\odot 2021$ by the authors. Licensee MDPI, Basel, Switzerland. This article is an open access article distributed under the terms and conditions of the Creative Commons Attribution (CC BY) license (https:// creativecommons.org/licenses/by/ $4.0 /)$.
Abstract: A graphene oxide aerogel (GOA) was formed inside a melamine sponge (MS) framework. After reduction with hydrazine at $60{ }^{\circ} \mathrm{C}$, the electrical conductive nitrogen-enriched rGOA-MS composite material with a specific density of $20.1 \mathrm{mg} / \mathrm{cm}^{3}$ was used to fabricate an electrode, which proved to be a promising electrocatalyst for the oxygen reduction reaction. The rGOA-MS composite material was characterized by elemental analysis, scanning electron microscopy, $\mathrm{X}$-ray photoelectron spectroscopy, and Raman spectroscopy. It was found that nitrogen in the material is presented by different types with the maximum concentration of pyrrole-like nitrogen. By using Raman scattering it was established that the rGOA component of the material is graphene-like carbon with an average size of the $\mathrm{sp}^{2}$-domains of $5.7 \mathrm{~nm}$. This explains a quite high conductivity of the composite obtained.

Keywords: reduced graphene oxide aerogel; melamine sponge; oxygen reduction reaction; lyophilization; composite material; linear sweep voltammetry

\section{Introduction}

Aerogels of graphene oxide (GO), reduced graphene oxide (rGO), and composites on their base are being actively studied [1-17]. These materials are of considerable interest due to their low specific density $\left(0.16 \mathrm{mg} / \mathrm{cm}^{3}\right.$ [1]) and high specific surface area (up to $960 \mathrm{~m}^{2} / \mathrm{g}$ [2]). Aerogels with high conductivity (up to $500 \mathrm{~S} / \mathrm{m}$ [5]) can be obtained by using special treatments and/or adding additives [3-5]. Modified aerogels can be used as catalysts, adsorbents of heavy metals, oils, and dyes, as well as sensors, electrodes for batteries and supercapacitors [7-11,18-23]. In addition, rGO aerogels are also used as materials for electrocatalysis [24-26].

From the point of view of practical applications, graphene-like materials have attracted great interest as catalysts for the oxygen reduction reaction (ORR) in fuel cell cathodes [27-30]. Reduced graphene oxide can be used as a carrier for catalyst nanoparticles composed of $\mathrm{Pt}$ and Pd as well as of their alloys [31-33] or transition metal oxides [28,34-36]. In addition, the graphene structures demonstrated excellent electrocatalytic activity towards ORR when doped with p-elements (N, S, P, and B) [27,28,30]. One of the most popular methods for obtaining N-doped graphene structures is the reduction of graphene oxide with hydrazine or ammonia [29,34,35,37]. In our previous work [38], we performed the reduction of a graphene 
oxide aerogel in hydrazine vapors and obtained conductive aerogel with a nitrogen content of $3 \mathrm{wt} \%$ and significant electrocatalytic activity towards ORR.

However, our experience has shown that the applicability of rGO aerogels without crosslinking (binding) agents is often limited by their fragility. Our experience is supported by the literature data. For example, graphene foam synthesized by a template chemical vapor deposition method is brittle and prone to fracture upon the removal of a thicker metal template [39]. Aerogels obtained by the hydrothermal or freeze-drying methods do crack due to the different heating or cooling rates of the outer and inner parts [23,40].

Crosslinking agents should improve the mechanical properties of aerogels, but they can alter the catalytic or absorption characteristics of rGO. It is interesting to produce openframe aerogels with suitable mechanical characteristics as an alternative solution. Suitable frameworks must have a low density and be chemically inert under ambient conditions. In principle, these criteria are met by melamine sponge, which has a high porosity of over $99 \%$, pore sizes of approximately $100 \mu \mathrm{m}$ [41], low density, excellent mechanical properties, and, most importantly, it is a cheap and ecologically clean product [41-44]. The trademark "melamine sponge" usually means a melamine-formaldehyde resin sponge whose chemical formula is presented in the Supporting Information (SI). Currently, there are a large number of publications in the literature describing new perspective applications of melamine sponge after its modification.

There are several works in which a melamine sponge was used in combination with graphene oxide or reduced graphene oxide [45-50]. In particular, the melamine/graphene sponge (M/GS) was prepared by a dip-coating method and low-temperature thermal reduction [45]. This M/GS was immersed into the carbon black/tetrahydrofuran (THF) dispersion and dried in air. In [46], an oil/water separation material with robust mechanical properties was developed by modifying a melamine sponge with silk fibroin-graphene oxide. The surface of the melamine sponge (MS) was also modified with polydopamine and then coated with glutathione/graphene oxide as an adsorbent for the removal of $\mathrm{Pb}(\mathrm{II})$ from aqueous solutions [47]. The superhydrophobic-reduced graphene oxide-modified melamine sponge may also be prepared via a facile ultrasonic-microwave synergistic method [48]. This material has shown high selectivity for trapping various oils and organic solvents from water, as well as excellent recyclability and stability. A significant part of the work on obtaining hydrophobic composites based on reduced graphene oxide and melamine sponge was aimed at separating water/oil mixtures (see, for example, [49,50]). To the best of our knowledge, there is no work in the literature where a graphene oxide aerogel was grown in the pores of a melamine sponge, and the GOA-MS composite reduced in hydrazine vapors was used as an electrocatalyst for the oxygen reduction reaction.

The present paper describes a method for preparing GO aerogel in open pores of a melamine sponge, thus forming a GOA-MS composite. Subsequent reduction with hydrazine vapors results in a rGOA-MS composite, which was characterized by elemental analysis, scanning electron microscopy (SEM), X-ray photoelectron spectroscopy (XPS), and Raman spectroscopy. One can anticipate that this composite will have many perspective applications. In this work, we describe the use of the rGOA-MS composite as a catalyst for the electroreduction of oxygen.

\section{Experimental}

Melamine sponge with a density of $9.8 \mathrm{mg} / \mathrm{cm}^{3}$ was manufactured by the JSC Accent (Saint Petersburg, Russia) from raw material from BASF SE (Ludwigshafen, Germany). For the GO synthesis, we used the modified Hummers method [51]. The GO production is described in detail in $[52,53]$ and Supporting Information (SI). The sponge was used in our experiments without additional pre-treatments. First, the sponge was impregnated by immersion into GO suspension $(17 \mathrm{mg} / \mathrm{mL})$ in distilled water. Next, the sponge was removed from the suspension and was slowly frozen on a copper plate cooled with liquid nitrogen. The frozen sponge was placed in a glass vessel with a silicone cup and lyophilized in a freeze dryer (model FDS5512 from IlShin BioBase, Dongducheon, Korea). The dried 
aerogel GOA-MS had a density of $26.7 \mathrm{mg} / \mathrm{cm}^{3}$. The aerogel was treated with hydrazine vapor to reduce GO, namely a portion of GOA-MS was placed in a sealed plastic vessel together with a portion of hydrazine hydrate $(4-5 \mathrm{~mL}$ in a Petri dish). The vessel was thermostated at $60{ }^{\circ} \mathrm{C}$ for $48 \mathrm{~h}$. The resulting reduced aerogel had a black color (Figure 1B), and its density was $20.1 \mathrm{mg} / \mathrm{cm}^{3}$.

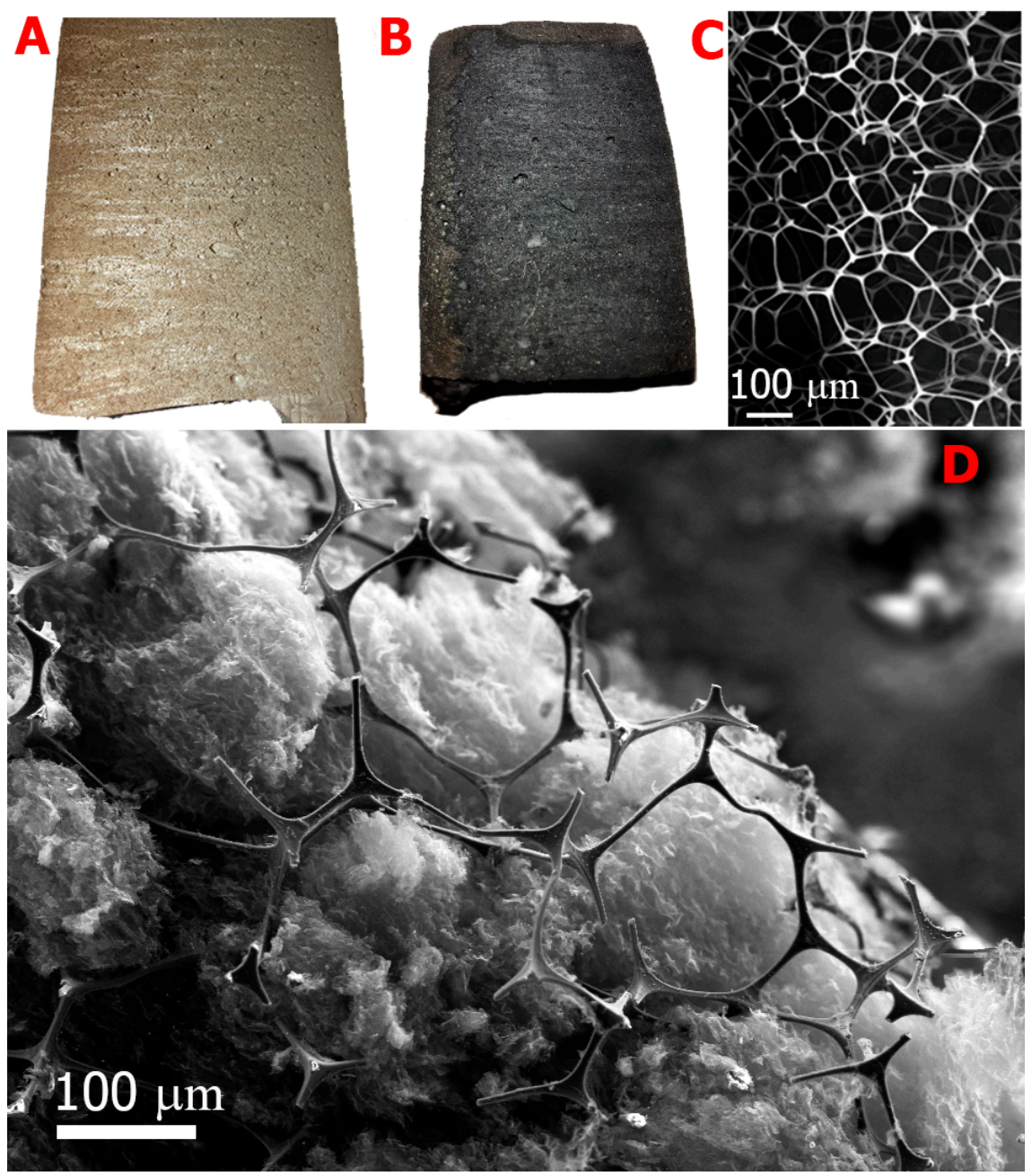

Figure 1. Optical images of GOA-MS (graphene oxide aerogel- melamine sponge): (A) rGOA (reduced graphene oxide)-MS, (B) SEM images of the MS, (C) rGOA-MS, and (D) samples fracture surface. The sample was fractured at the temperature of liquid nitrogen.

The elemental analysis of the samples for the content of $\mathrm{C}, \mathrm{H}, \mathrm{N}$, and $\mathrm{S}$ was carried out on an analyzer, the "VarioMicrocube" Elementar GmbH (Hanau, Germany). Raman spectra were recorded with the use of the Bruker Senterra micro-Raman system. The excitation wavelength was $532 \mathrm{~nm}$ and the laser power was $1 \mathrm{~mW}$ at the sample point with a beam waist of $\sim 1 \mu \mathrm{m}$. The contact water-wetting angle was measured on an OCA 20 instrument (Data Physics Instruments $\mathrm{GmbH}$, Filderstadt, Germany) at room temperature. Electron micrographs were obtained with a JEOL JSM-5910LV scanning electron microscope (JEOL Ltd., Tokyo, Japan) (electron energy $20 \mathrm{kV}$, chamber pressure $2 \times 10^{-5} \mathrm{~Pa}$ ).

XPS spectra were obtained using a Specs PHOIBOS 150 MCD electron spectrometer (SPECS GmbH, Berlin, Germany) with a Mg cathode ( $h v=1253.6 \mathrm{eV})$. The vacuum in the spectrometer chamber did not exceed $4 \times 10^{-8} \mathrm{~Pa}$. The survey spectra were recorded in the constant transmission energy mode of $40 \mathrm{eV}$ whereas the individual lines were recorded with $10 \mathrm{eV}$. The survey spectra and individual lines were recorded in $1.00 \mathrm{eV}$ and $0.03 \mathrm{eV}$ increments, respectively. The background subtraction was carried out according 
to the Shirley method [54], and the spectra decomposition into mixed Gaussian-Lorentz peaks was performed using the Casa XPS software (version 2.3.19, Casa Software Ltd, Teignmouth, UK). Quantification of atomic content was done using the sensitivity factors from the CasaXPS elemental library.

The linear sweep voltammetry (LSV) was performed in a three-electrode cell using the set-up with a RRDE-3A rotating disk electrode (ALS Co., Ltd., Tokyo, Japan) and an Autolab PGSTAT302N (Metrohm Autolab, Utrecht, The Netherlands) in an $\mathrm{O}_{2}$-saturated solution of $0.1 \mathrm{M} \mathrm{KOH}$ at a potential scan rate of $v=10 \mathrm{mV} / \mathrm{s}$ and electrode rotation rates $\omega=360-6400 \mathrm{rpm}$. The analysis of voltammetry results was carried out within the Koutecký-Levich equation [55]:

$$
\frac{1}{j}=\frac{1}{j_{k}}+\frac{1}{j_{d}}
$$

where $j_{\mathrm{k}}=n \mathrm{Fk} c^{0}$ and $j_{\mathrm{d}}=0.62 n \mathrm{FD}^{2 / 3} \omega^{1 / 2} v^{-1 / 6} c^{0}$ are the kinetic current density and the limiting diffusion current density, respectively, $\mathrm{F}$ is the Faraday constant $(\mathrm{F}=96,485 \mathrm{C} / \mathrm{mol})$, $n$ is the number of electrons participating in the electrode reaction, $k$ is the oxygen reduction rate constant, $\mathrm{D}$ is the coefficient of oxygen diffusion in $0.1 \mathrm{M} \mathrm{KOH}\left(\mathrm{D}=1.9 \times 10^{-5} \mathrm{~cm}^{2} / \mathrm{s}\right)$, $v$ is the kinematic viscosity of $0.1 \mathrm{M} \mathrm{KOH}\left(v=0.01 \mathrm{~cm}^{2} / \mathrm{s}\right)$, and $c^{0}$ is the bulk concentration of dissolved oxygen $\left(c^{0}=1.2 \times 10^{-3} \mathrm{M}\right.$ in $\left.0.1 \mathrm{M} \mathrm{KOH}\right)[56,57]$.

The rGOA-MS composite was ground in liquid nitrogen in a nephrite jade mortar and the resulting powder was dispersed in water using a powerful ultrasonic disperser. A glassy carbon (GC) disk of $3 \mathrm{~mm}$ in diameter pressed into PEEK polymer was used as a working electrode. The surface of the initial GC electrode was polished with $1 \mu \mathrm{m}$ of $\mathrm{Al}_{2} \mathrm{O}_{3}$ powder. Then, ca. $5 \mu \mathrm{L}$ of the rGOA-MS suspension $(0.5 \mathrm{mg} / \mathrm{mL})$ with ca. $0.01 \mathrm{wt} \%$ Nafion polymer added was drop-casted on the GC surface and dried at ambient temperature. Platinum wire with a $1 \mathrm{~cm}^{2}$ surface area was an auxiliary electrode; a reference electrode was represented by an $\mathrm{Ag} / \mathrm{AgCl}$ (saturated $\mathrm{KCl}$ ) electrode. All potentials $(E)$ were converted to the reversible hydrogen electrode $(\mathrm{RHE})$ scale $\left(E_{\mathrm{RHE}}=E_{(\mathrm{Ag} / \mathrm{AgCl})}+0.964 \mathrm{~V}\right)$.

\section{Results and Discussion}

\subsection{Elemental Analysis}

The data on our sample compositions are presented in Table 1. Minor amounts of sulfur can be present in GO obtained by the Hummers technique (see, for example, [58]). The technological impurities of melamine sponge may also contain sulfur. The GO content in the composite can be estimated by taking into account the fact that $\mathrm{GO}$ contains negligible amount of nitrogen. This gives $74 \mathrm{wt} \%$ of GO in GOA-MS. The tests show that the hydrazine vapor treatment induces no change in the melamine sponge. Therefore, chemical changes upon the transition from GOA-MS to rGOA-MS should be attributed to GO only. Table 1 shows a pronounced reduction of GO at this stage (the oxygen content decreases). Nitrogen content in rGOA-MS becomes significantly higher. High nitrogen content may indicate good performance of the material as an electrocatalyst for oxygen reduction [59]).

Table 1. Elemental composition (in wt $\%$ ) of the samples under study. MS: Melamine sponge.

\begin{tabular}{cccccc}
\hline Sample & $\mathbf{C}$ & $\mathbf{H}$ & $\mathbf{N}$ & $\mathbf{S}$ & $\mathbf{O}^{*}$ \\
\hline MS & $35.40 \pm 0.22$ & $5.164 \pm 0.039$ & $43.84 \pm 0.28$ & $1.325 \pm 0.021$ & 14.27 \\
\hline GOA-MS & $41.65 \pm 0.18$ & $3.750 \pm 0.074$ & $17.40 \pm 0.36$ & $1.727 \pm 0.058$ & 35.47 \\
\hline rGOA-MS & $53.34 \pm 0.76$ & $3.179 \pm 0.061$ & $27.50 \pm 0.92$ & $1.500 \pm 0.106$ & 14.48 \\
\hline * oxygen content was estimated by the formula $[\mathrm{O}]=100$ & \multicolumn{2}{c}{$\sum_{\mathrm{i}}\left[\mathrm{C}_{i}\right]$, where $\left[C_{i}\right]$ is the content of the $i$-th element. }
\end{tabular}

\subsection{SEM}

The SEM images of the initial MS and rGOA-MS composite are shown in Figure 1. It may be seen that the average pore size in MS is equal to approximately $100-200 \mu \mathrm{m}$, 
and a relatively loose rGO substance is uniformly distributed inside the melamine sponge framework.

\subsection{Raman Spectra}

Micro-Raman spectroscopy makes it possible to study the areas with predominant distributions of rGO and MS separately. The spectra for two different spots in the rGOAMS composite are shown in Figure 2. In spectrum 1 corresponding to the MS, the most intense peak at $985 \mathrm{~cm}^{-1}$ belongs to the $\mathrm{CNC}+\mathrm{NCN}$ bending vibration of the triazine ring [60-64]. In spectrum 2, two dominant features are the D and G bands of the graphenelike carbon [65] and wide band at $\sim 2700 \mathrm{~cm}^{-1}$. For graphene, the 2D peak is typically observed at $2700 \mathrm{~cm}^{-1}$. For multi-layer graphene, the position may be shifted to lower energies. For GO, the typical position is close to that of a graphene monolayer [66], but the width is significantly higher (FWHM $200 \mathrm{~cm}^{-1}$ as compared to $24 \mathrm{~cm}^{-1}$ for the graphene monolayer).

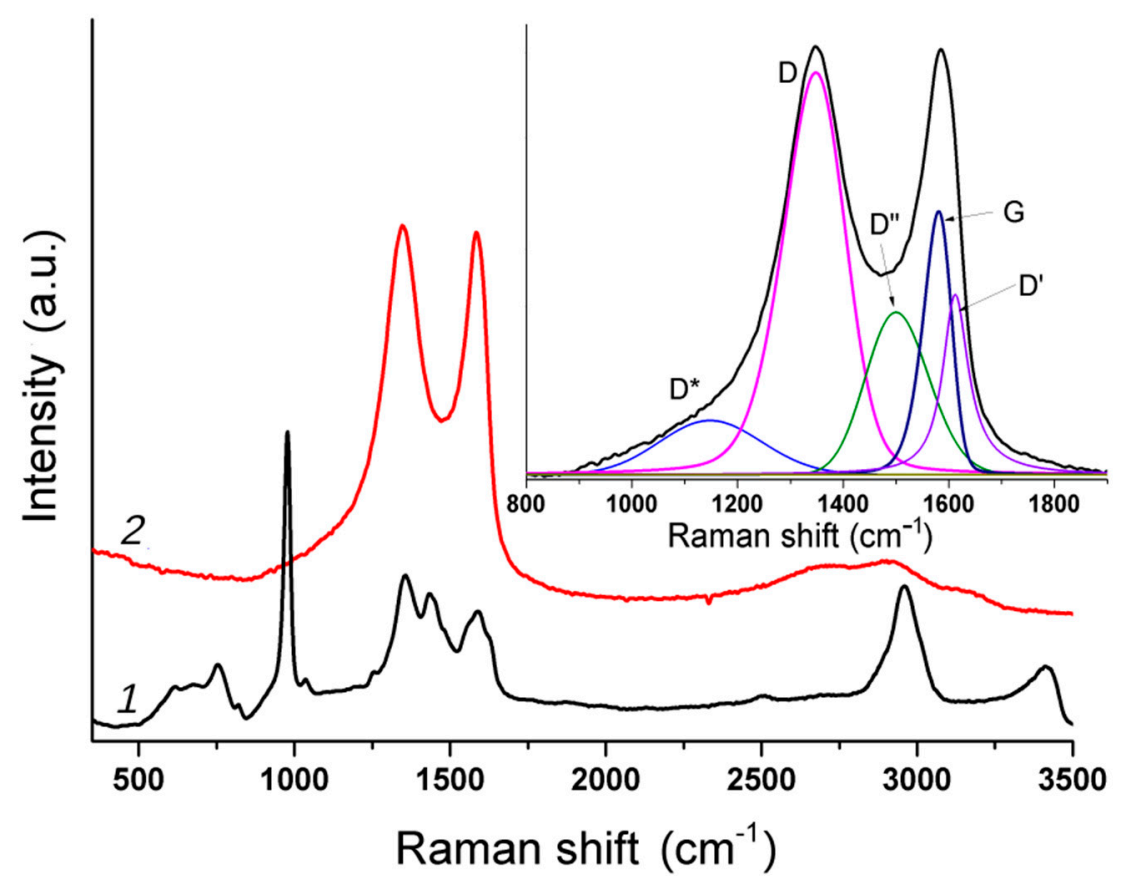

Figure 2. Micro-Raman spectra of the rGOA-MS composite taken from two spots with the dominant contribution of MS (1) and rGO (2). The inset shows a deconvolution of the rGO spectrum into separate peaks as suggested in [67].

The Raman spectrum of rGO was deconvoluted into five peaks as it was previously suggested [67]. Prior to deconvolution, the background was subtracted by the algorithm described elsewhere [68]. The peak shapes were approximated with the flexible pseudoVoigt profiles [69]. The positions, half-widths, and relative intensities of the resulting fitting functions are shown in Table 2. 
Table 2. The positions (Pos), full widths at half maximum (FWHM), and intensities (Int) of the peaks in the Raman spectrum of rGOA-MS.

\begin{tabular}{cccc}
\hline Peak & Pos, $\mathbf{c m}^{-1}$ & FWHM, $\mathbf{c m}^{-1}$ & Int, $\%$ \\
\hline $\mathrm{D}^{*}$ & 1148 & 227 & 10 \\
\hline $\mathrm{D}$ & 1348 & 138 & 46 \\
\hline $\mathrm{D}^{\prime \prime}$ & 1500 & 140 & 18 \\
\hline $\mathrm{G}$ & 1581 & 62 & 14 \\
\hline $\mathrm{D}^{\prime}$ & 1612 & 58 & 12 \\
\hline
\end{tabular}

The ratio between the $\mathrm{D}$ and $\mathrm{G}$ band intensities $\left(I_{D} / I_{G}\right)$ can serve as a disorder measure in the carbon lattice. The $I_{D} / I_{G}$ values can also be used to evaluate the size of the $s p^{2}$ domains $L_{a}[65]$ as follows:

$$
L_{a}=\left(2.4 \times 10^{-10}\right) \lambda^{4}{ }_{\mathrm{L}}\left(I_{D} / I_{G}\right)^{-1}
$$

where $\lambda_{\mathrm{L}}$ is the wavelength (in $\mathrm{nm}$ ) of the excitation laser. The domain size $L_{a}$ estimated from Equation (2) equals to $5.7 \mathrm{~nm}$ for the rGOA-MS material.

\subsection{XPS}

Figure 3 shows the survey XPS spectra of the rGOA-MS sample. The elemental composition of the surface, calculated using the integral intensities of the analytical lines (marked in the figure), corresponds to formula $\mathrm{C}_{0.88} \mathrm{O}_{0.08} \mathrm{~N}_{0.03} \mathrm{~S}_{0.01}$. The surface composition is different from that of the bulk (see Table 1). In particular, the surface has lower nitrogen and oxygen concentrations. The nitrogen depletion at the surface may indicate a low electrocatalytic efficiency of rGOA-MS for oxygen reduction. However, this result is not conclusive because the surfaces accessed in the XPS experiment and involved into the redox reaction may be different.

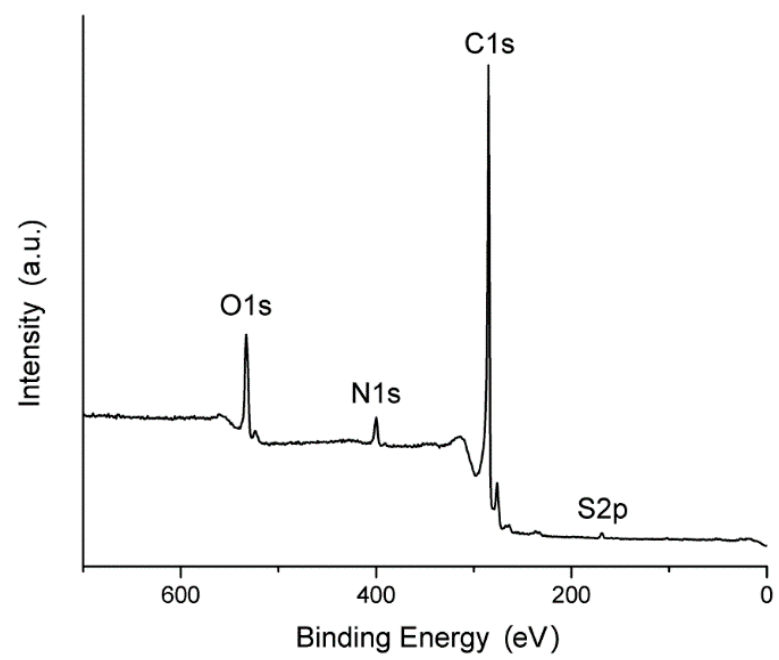

Figure 3. The XPS survey spectrum of the rGOA-MS sample.

The $\mathrm{C}$ 1s line shape and its deconvolution into six symmetric pseudo-Voigt profiles is displayed in Figure 4A. The binding energies and peak intensities are presented in Table S3 (see Supporting Information). The dominant peak is located at $284.6 \mathrm{eV}$, which is typical for $s p^{2}$ carbon materials. The second intense peak at $285.9 \mathrm{eV}$ can be assigned to the carbon atoms single-bonded to oxygen or nitrogen, i.e., to hydroxy- and epoxy-groups, respectively, and also to pyridine and pyrrole nitrogen. The contributions of these groups cannot be reliably separated. 

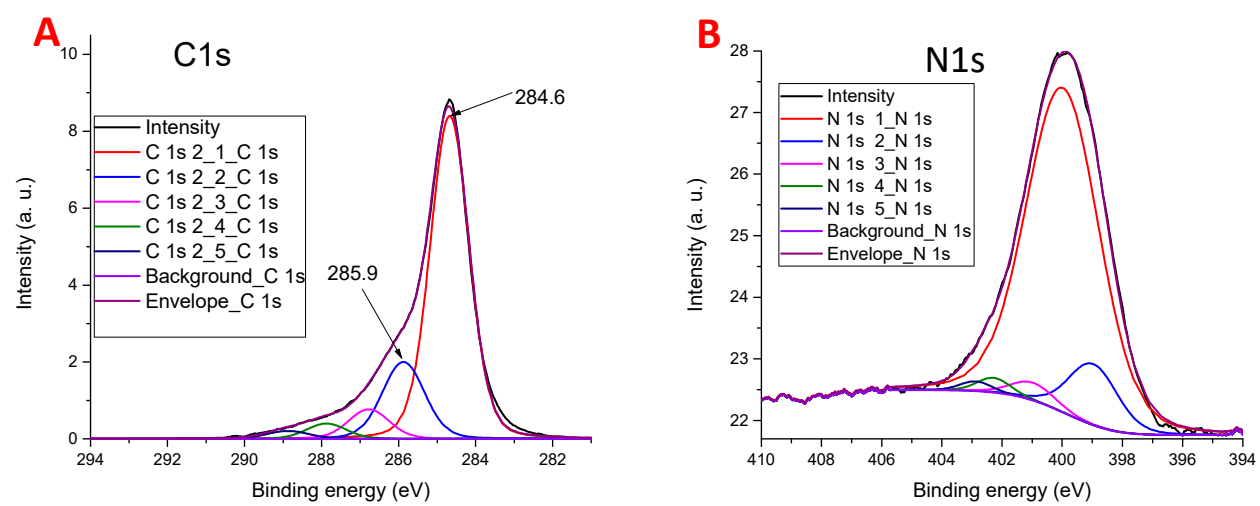

Figure 4. The C 1s (A) and N 1s (B) spectra of the rGOA-MS sample.

The $\mathrm{N} 1 s$ structure allows one to identify the presence of surface nitrogen-containing groups. Nitrogen in graphite-like matrix can exist [70] in the following configurations: Pyridine-like (N1), pyrrole (5-membered cycle) (N2), graphite-like N (N3, N4), and oxidized pyridine $\mathrm{N}(\mathrm{N} 5)$. The $\mathrm{N} 1$ and $\mathrm{N} 2$ atoms are located at the edges of the graphene layers or at the defect sites. The graphite-like N3 and N4 substitute carbon atoms in the graphene layer at the edges (N3) and in the center (N4). The pyridine-like N1 can present also in the oxidized form (N5).

The XPS peak positions for these nitrogen types are well known (see [70] and references therein). N1 corresponds to a peak at 398.0-399.3 eV, N2 corresponds to a peak around 399.8-401.2 eV, N4 corresponds to a peak close to $401 \mathrm{eV}$, and N3 corresponds to a peak around $402.3 \mathrm{eV}$. The highest energy of $402.8 \mathrm{eV}$ has a peak corresponding to the oxidized pyridine type $\mathrm{N} 4$.

In the sample studied, the most intense $\mathrm{N}$ 1s peak is located at $400.1 \mathrm{eV}$ (see Figure 4B and Table S4 in Supporting Information). This main peak can belong to pyrrole-like (N2) as well as to the graphite-like (N4) structures. A minor peak (with about $10 \%$ of the total N $1 s$ intensity), which can be distinguished at $399.1 \mathrm{eV}$, can safely be assigned to the pyridine-like nitrogen (N1). In the previous work [71], based on the use of the model catalysts, it was shown that pyridine-like nitrogen plays the role of an active center for oxygen reduction under acidic conditions.

\subsection{Oxygen Reduction Reaction}

The linear sweep voltammetry carried out in a solution of $0.1 \mathrm{M} \mathrm{KOH}$ saturated with oxygen for the glassy carbon electrode loaded with rGOA-MS as well as for the initial GC are presented in Figure 5 (the electrode rotation rate was $2000 \mathrm{rpm}$ and the potential scan rate was $10 \mathrm{mV} / \mathrm{s}$ ). Based on the results of processing voltammograms measured at different electrode rotation rates (Figure 6A), from the slope of Koutecký-Levich (KL) plots (Figure 6B) and in accordance with Equation (1), the number of electrons $n$ participating in the oxygen reduction reaction were defined at various potentials in Figure 7. The inset in Figure 7 depicts Tafel plots for the investigated objects. The slopes of lines are $50.3 \mathrm{mV} / \mathrm{dec}$ and $33.8 \mathrm{mV} / \mathrm{dec}$ for the initial GC and rGOA-MS, respectively, which are consistent with the values reported in the literature [72,73]. As can be seen from Figure 5, the GC electrode coated with rGOA-MS demonstrates somewhat higher oxygen reduction currents than the initial GC. On the LSV curve for rGOA-MS (curve 2 in Figure 5), two distinct waves can be distinguished, which correspond to the reduction of oxygen to hydrogen peroxide in the potential range from $300 \mathrm{mV}$ to $650 \mathrm{mV}(\mathrm{n} \approx 2)$ and water at $E<100 \mathrm{mV}(n \approx 3.4-3.5)$. Thus, a noticeable catalytic effect towards the oxygen reduction reaction is observed for rGOA-MS, namely, there is a ca. $60 \mathrm{mV}$ decrease in the ORR overpotential and higher values of $n$ are observed for rGOA-MS at $E<300 \mathrm{mV}$ as compared to glassy carbon. The results obtained are less prominent as it was for a reduced graphene oxide aerogel [38], which demonstrated a ca. $90 \mathrm{mV}$ decrease in ORR overpotential and higher values of the electron transfer number $(\mathrm{n} \approx 2.4-2.8$ in the potential range from $350 \mathrm{mV}$ to $550 \mathrm{mV}$ ). 
Evidently, the observed effect is rather small, which is caused by a low concentration of active centers (surface defects, edge regions of graphene-like structures, and dopant atoms embedded into graphene layers) on the surface of rGOA-MS for the adsorption of both $\mathrm{O}_{2}$ and intermediates of its reduction. It can be assumed that in accordance with [23], insufficient catalytic activity of rGOA-MS is due to the low surface concentration of pyridine-like nitrogen. The thermal treatment of the composite could likely increase the surface concentration of nitrogen. Moreover, the melamine sponge in the composite also affects the total concentration of active centers, which is lower than that for a reduced graphene oxide aerogel [38].

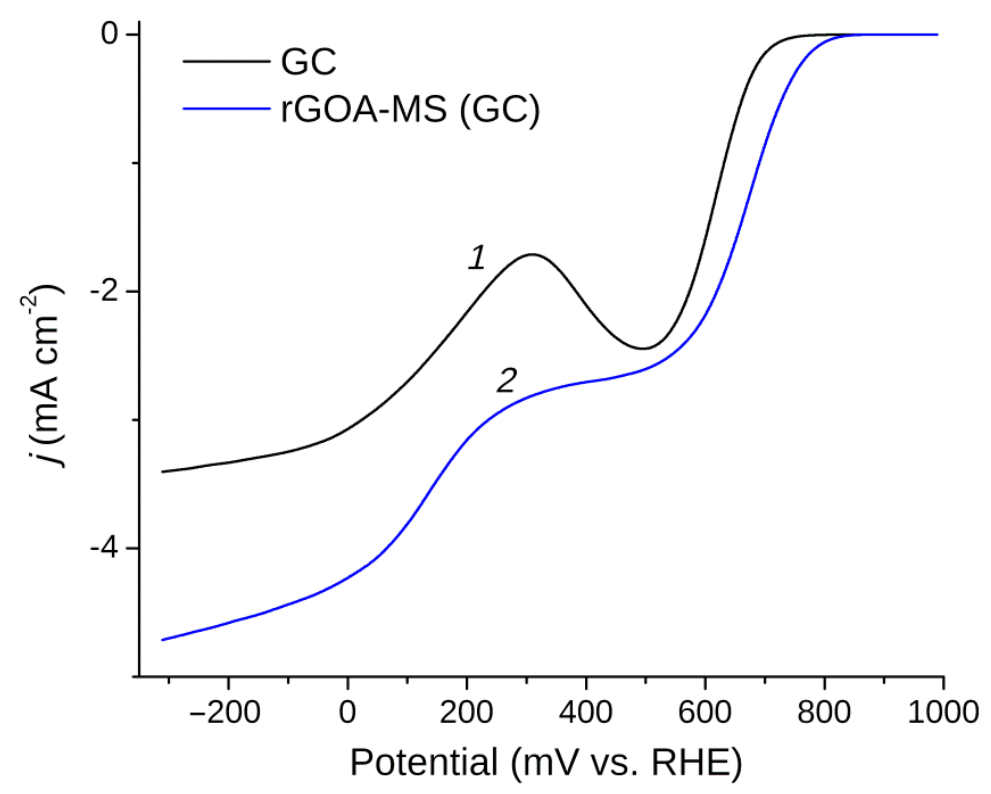

Figure 5. Linear sweep voltammetry in an $\mathrm{O}_{2}$-saturated solution of $0.1 \mathrm{M} \mathrm{KOH}$ for the glassy carbon (GC) electrode (1) and GC coated with rGOA-MS (2), v= $10 \mathrm{mV} / \mathrm{s}, \omega=2000 \mathrm{rpm}$.
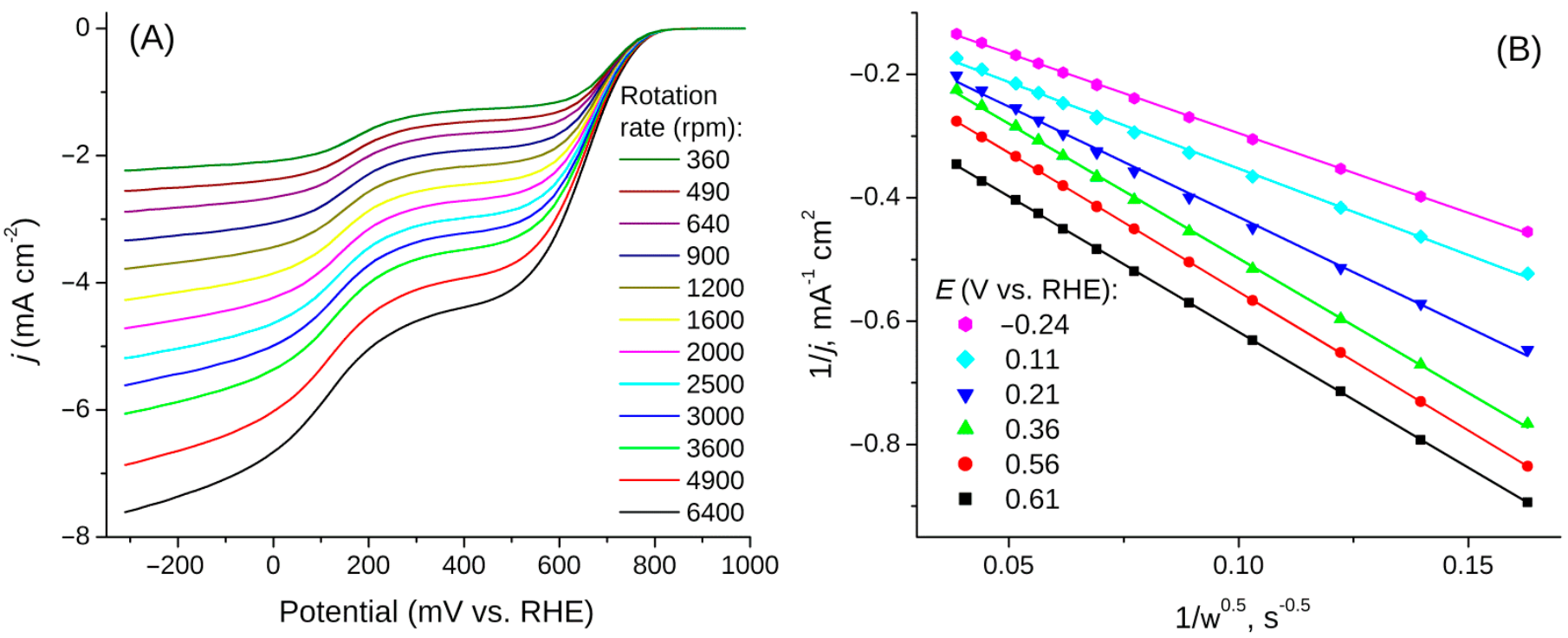

Figure 6. The LSVs at the GC electrode coated with rGOA-MS at different electrode rotation rates, $v=10 \mathrm{mV} / \mathrm{s}(\mathbf{A})$; K-L plots at selected potentials (B). 


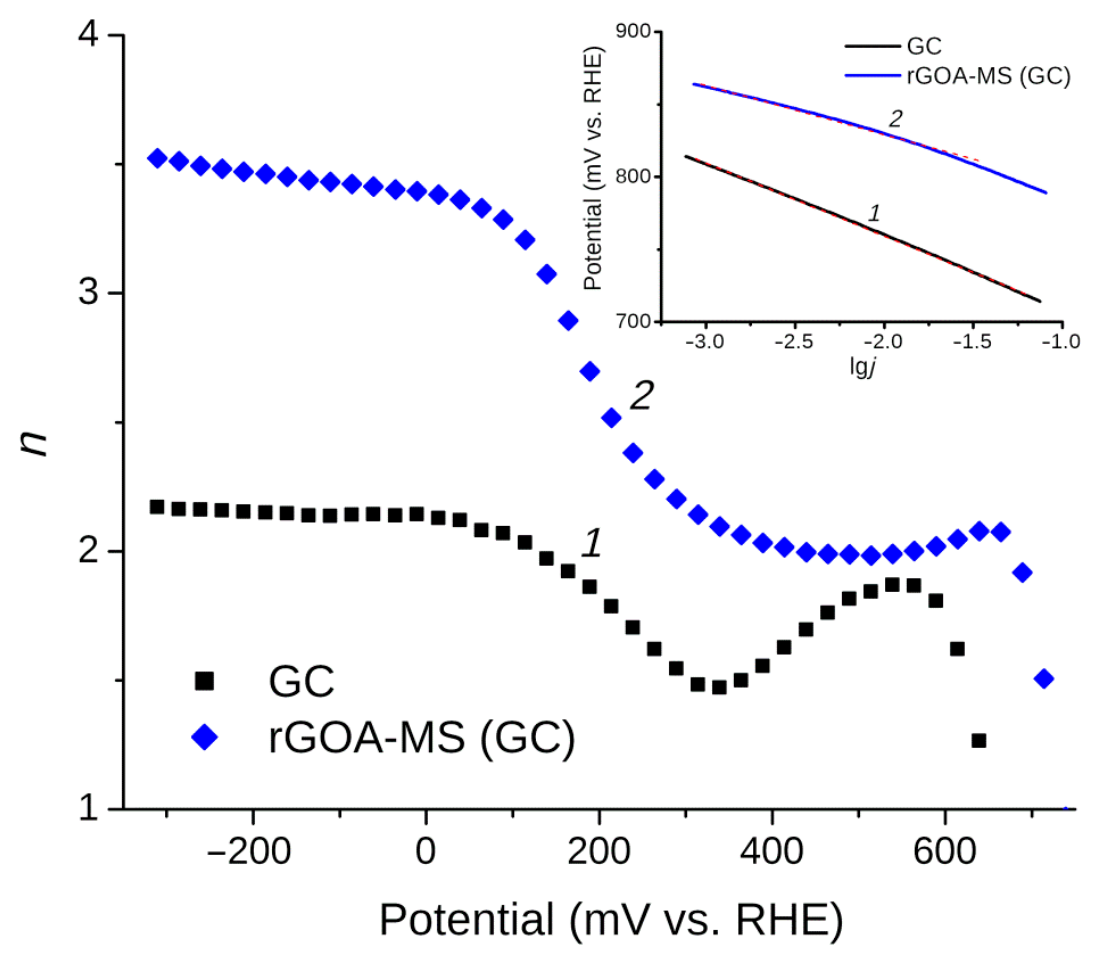

Figure 7. $n$ vs. potential for the GC electrode (1) and GC coated with rGOA-MS (2).

\section{Conclusions}

The freeze-drying of GO in a melamine sponge framework resulted in the formation of a GOA-MS composite where the GO aerogel was uniformly distributed over the MS structure. This material was reduced with hydrazine to yield the rGOA-MS. The method of obtaining our composites differs significantly from the classical method of producing nanocarbon 3D structures by the infiltration of a porous substrate [74]. The structure of our carbon 3D material was determined not by the porous structure of the substrate, but by the ratio of water and graphene oxide of the hydrogel, as well as by the freezedrying procedure and subsequent treatments. Elemental analysis showed that the resulting composite had a high nitrogen content of $27 \%$, whereas the surface concentration of nitrogen estimated from the XPS spectra was significantly lower. The XPS-estimated composition of rGOA-MS corresponded to the formula $\mathrm{C}_{0.88} \mathrm{O}_{0.08} \mathrm{~N}_{0.03} \mathrm{~S}_{0.01}$. The tests showed that the rGOA-MS composite had a pronounced electrocatalytic activity towards oxygen reduction reaction. The catalytic efficiency could be enhanced by increasing the near-surface content of nitrogen.

Supplementary Materials: The following are available online at https:/ / www.mdpi.com/1996-1 944/14/2/322/s1, Figure S1: The survey XPS spectrum of a GO film; Figure S2: The C 1s XPS spectra of GO films and their decomposition; Figure S3: A Raman spectrum of GO; Figure S4: Microphotographs of GO nanosheets; Figure S5: Microphotographs of GO paper: A corresponds to the bright side; B corresponds to the matt side; Figure S6: Microphotograph of a GO film cross section; Figure S7: Melamine-formaldehyde (chemical formula); Table S1: The results of approximation of the XPS C 1 s spectrum of the GO film: $\mathrm{C} 1$ s binding energies $(B E$, in $\mathrm{eV})$ and relative peak intensities $(I$, arbitrary units); Table S2: Positions of the peak maxima and ratios of integral intensities of the major bands in the Raman spectra of GO samples obtained by different research groups; Table S3: Results of C 1s spectrum decomposition for composite aerogel rGOA-MS; Table S4: Results of N 1s spectrum decomposition for composite aerogel rGOA-MS.

Author Contributions: R.A.M.: Investigation, conceptualization, formal analysis, writing the original draft. S.A.B.: Investigation, formal analysis, visualization, editing draft. E.N.K.: Investigation, formal analysis, visualization, reviewing and editing the original draft. V.I.K.: Investigation, formal analysis. N.N.D.: Investigation. Y.V.B.: Investigation, formal analysis. A.G.K.: Conceptualization, writing 
and editing the drafts. Y.M.S.: Conceptualization, methodology, writing and editing the drafts, supervision. G.L.G., finalization of the work and submission. All authors have read and agreed to the published version of the manuscript.

Funding: This work was supported by the Ministry of Science and Higher Education of the Russian Federation in the frame of state program of basic research "For the long-term development and ensuring the competitiveness of society and the state" (47 GP) on the base of the universities, the plan of basic scientific research No. 718/20 dated 03/06/2020 (project No. 0718-2020-0036) and the Federal Target Program (Project UI RFMEFI60419x0235), and was performed in the frame of the state tasks, state registration Nos AAAA-A19-119061890019-5, AAAA-A19-119032690060-9, and 075-15-2020-791.

Institutional Review Board Statement: Not applicable.

Informed Consent Statement: Not applicable.

Data Availability Statement: Data available in a publicly accessible repository.

Acknowledgments: The work used the equipment of the Multi-User Analytical Center of IPCP RAS, and the Chernogolovka Scientific Center RAS. This study was conducted using resources from the Competence Center of National Technology Initiative in IPCP RAS.

Conflicts of Interest: The authors declare no conflict of interest.

\section{References}

1. Sun, H.; Xu, Z.; Gao, C. Multifunctional, ultra-flyweight, synergistically assembled carbon aerogels. Adv. Mater. 2013, 25, 2554-2560. [CrossRef] [PubMed]

2. Zhang, L.; Shi, G. Preparation of Highly Conductive Graphene Hydrogels for Fabricating Supercapacitors with High-Rate Capability. J. Phys. Chem. C 2011, 115, 17206-17212. [CrossRef]

3. Worsley, M.A.; Pauzauskie, P.J.; Olson, T.Y.; Biener, J.; Satcher, J.H., Jr.; Baumann, T.F. Synthesis of graphene aerogel with high electrical conductivity. J. Am. Chem. Soc. 2010, 132, 14067-14069. [CrossRef] [PubMed]

4. Zhang, X.; Sui, Z.; Xu, B.; Yue, S.; Luo, Y.; Zhan, W.; Liu, B. Mechanically strong and highly conductive graphene aerogel and its use as electrodes for electrochemical power sources. J. Mater. Chem. 2011, 21, 6494-6497. [CrossRef]

5. Pham, H.D.; Pham, V.H.; Cuong, T.V.; Nguyen-Phan, T.-D.; Chung, J.S.; Shin, E.W.; Kim, S. Synthesis of the chemically converted graphene xerogel with superior electrical conductivity. Chem. Commun. 2011, 47, 9672-9674. [CrossRef] [PubMed]

6. Gorgolis, G.; Galiotis, C. Graphene aerogels: A review. 2D Mater. 2017, 4, 032001. [CrossRef]

7. Pierre, A.C.; Pajonk, G.M. Chemistry of aerogels and their applications. Chem. Rev. 2002, 102, 4243-4265. [CrossRef]

8. Chen, W.; Li, S.; Chen, C.; Yan, L. Self-assembly and embedding of nanoparticles by in situ reduced graphene for preparation of a 3D graphene/nanoparticle aerogel. Adv. Mater. 2011, 23, 5679-5683. [CrossRef]

9. Wang, R.; Xu, C.; Sun, J.; Gao, L. Three-dimensional $\mathrm{Fe}_{2} \mathrm{O}_{3}$ nanocubes/nitrogen-doped graphene aerogels: Nucleation mechanism and lithium storage properties. Sci. Rep. 2014, 4, 7171. [CrossRef]

10. Cong, H.-P.; Ren, X.-C.; Wang, P.; Yu, S.-H. Macroscopic multifunctional graphene-based hydrogels and aerogels by a metal ion induced self-assembly process. ACS Nano 2012, 6, 2693-2703. [CrossRef]

11. Liu, X.; Cui, J.; Sun, J.; Zhang, X. 3D graphene aerogel-supported $\mathrm{SnO}_{2}$ nanoparticles for efficient detection of $\mathrm{NO}_{2}$. RSC Adv. 2014, 4, 22601-22605. [CrossRef]

12. Lobach, A.S.; Kazakov, V.A.; Spitsyna, N.G.; Baskakov, S.A.; Dremova, N.N.; Shulga, Y.M. Comparative study of graphene aerogels synthesized using sol-gel method by reducing graphene oxide suspension. High Energy Chem. 2017, 51, 269-276. [CrossRef]

13. Zhao, W.; Lu, X.; Selvaraj, M.; Wei, W.; Jiang, Z.; Ullah, N.; Liu, J.; Xie, J. MXP (M=Co/Ni)@ carbon core-shell nanoparticles embedded in 3D cross-linked graphene aerogel derived from seaweed biomass for hydrogen evolution reaction. Nanoscale 2018, 10, 9698-9706. [CrossRef] [PubMed]

14. Liu, Q.; Shen, J.; Yang, X.; Zhang, T.; Tang, H. 3D reduced graphene oxide aerogel-mediated Z-scheme photocatalytic system for highly efficient solar-driven water oxidation and removal of antibiotics. Appl. Catal. B 2018, 232, 562-573. [CrossRef]

15. Gu, J.; Hu, C.; Zhang, W.; Dichiara, A.B. Reagentless preparation of shape memory cellulose nanofibril aerogels decorated with Pd nanoparticles and their application in dye discoloration. Appl. Catal. B 2018, 237, 482-490. [CrossRef]

16. Ma, Y.; Yue, Y.; Zhang, H.; Cheng, F.; Zhao, W.; Rao, J.; Luo, S.; Wang, J.; Jiang, X.; Liu, Z.; et al. 3D Synergistical MXene/Reduced Graphene Oxide Aerogel for a Piezoresistive Sensor. ACS Nano 2018, 12, 3209-3216. [CrossRef]

17. Nagy, B.; Bakos, I.; Bertóti, I.; Domán, A.; Menyhárd, A.; Mohai, M.; László, K. Synergism of nitrogen and reduced graphene in the electrocatalytic behavior of resorcinol-Formaldehyde based carbon aerogels. Carbon 2018, 139, 872-879. [CrossRef]

18. Xu, L.; Xiao, G.; Chen, C.; Li, R.; Mai, Y.; Sun, G.; Yan, D. Superhydrophobic and superoleophilic graphene aerogel prepared by facile chemical reduction. J. Mater. Chem. A 2015, 3, 7498-7504. [CrossRef]

19. Bi, H.; Xie, X.; Yin, K.; Zhou, Y.; Wan, S.; He, L.; Xu, F.; Banhart, F.; Sun, L.; Ruoff, R.S. Graphene: Spongy Graphene as a Highly Efficient and Recyclable Sorbent for Oils and Organic Solvents. Adv. Funct. Mater. 2012, 22, 4401. [CrossRef] 
20. Wang, J.; Shi, Z.; Fan, J.; Ge, Y.; Yin, J.; Hu, G. Self-assembly of graphene into three-dimensional structures promoted by natural phenolic acids. J. Mater. Chem. 2012, 22, 22459-22466. [CrossRef]

21. Wu, T.; Chen, M.; Zhang, L.; Xu, X.; Liu, Y.; Yan, J.; Wang, W.; Gao, J. Three-dimensional graphene-based aerogels prepared by a self-assembly process and its excellent catalytic and absorbing performance. J. Mater. Chem. A 2013, 1, 7612-7621. [CrossRef]

22. Huang, X.; Sun, B.; Su, D.; Zhao, D.; Wang, G. Soft-template synthesis of 3D porous graphene foams with tunable architectures for lithium $-\mathrm{O}_{2}$ batteries and oil adsorption applications. J. Mater. Chem. A 2014, 2, 7973-7979. [CrossRef]

23. Baskakov, S.A.; Baskakova, Y.V.; Kabachkov, E.N.; Dremova, N.N.; Michtchenko, A.; Shulga, Y.M. Novel Superhydrophobic Aerogel on the Base of Polytetrafluoroethylene. ACS Appl. Mater. Interfaces 2019, 11, 32517-32522. [CrossRef] [PubMed]

24. Luo, Z.; Tan, C.; Zhang, X.; Chen, J.; Cao, X.; Li, B.; Zong, Y.; Huang, L.; Huang, X.; Wang, L.; et al. Preparation of Cobalt Sulfide Nanoparticle-Decorated Nitrogen and Sulfur Co-Doped Reduced Graphene Oxide Aerogel Used as a Highly Efficient Electrocatalyst for Oxygen Reduction Reaction. Small 2016, 12, 5920-5926. [CrossRef]

25. Gu, Y.; Chen, S.; Ren, J.; Jia, Y.A.; Chen, C.; Komarneni, S.; Yang, D.; Yao, X. Electronic Structure Tuning in Ni3FeN/r-GO Aerogel toward Bifunctional Electrocatalyst for Overall Water Splitting. ACS Nano 2018, 12, 245-253. [CrossRef]

26. Xiong, C.; Yang, Q.; Dang, W.; Li, M.; Li, B.; Su, J.; Liu, Y.; Zhao, W.; Duan, C.; Dai, L.; et al. Fabrication of eco-friendly carbon microtubes@ nitrogen-doped reduced graphene oxide hybrid as an excellent carbonaceous scaffold to load $\mathrm{MnO}_{2}$ nanowall (PANI nanorod) as bifunctional material for high-performance supercapacitor and oxygen reduction reaction catalyst. J. Power Sources 2020, 447, 227387.

27. Sheng, Z.H.; Shao, L.; Chen, J.J.; Bao, W.J.; Wang, F.B.; Xia, X.H. Catalyst-free synthesis of nitrogen-doped graphene via thermal annealing graphite oxide with melamine and its excellent electrocatalysis. ACS Nano 2011, 5, 4350-4358. [CrossRef]

28. Dai, L.; Xue, Y.; Qu, L.; Choi, H.-J.; Baek, J.-B. Metal-free catalysts for oxygen reduction reaction. Chem. Rev. 2015, 115, 4823-4892. [CrossRef]

29. He, Q.; Cairns, E.J. Recent progress in electrocatalysts for oxygen reduction suitable for alkaline anion exchange membrane fuel cells. J. Electrochem. Soc. 2015, 162, F1504. [CrossRef]

30. Shah, A.; Zahid, A.; Subhan, H.; Munir, A.; Iftikhar, F.J.; Akbar, M. Heteroatom-doped carbonaceous electrode materials for high performance energy storage devices. Sustain. Energy Fuels 2018, 2, 1398-1429. [CrossRef]

31. Li, Y.; Li, Y.; Zhu, E.; McLouth, T.; Chiu, C.-Y.; Huang, X.; Huang, Y. Stabilization of high-performance oxygen reduction reaction Pt electrocatalyst supported on reduced graphene oxide/carbon black composite. J. Am. Chem. Soc. 2012, 134, 12326-12329. [CrossRef] [PubMed]

32. Seo, M.H.; Choi, S.M.; Lee, D.U.; Kim, W.B.; Chen, Z. Correlation between theoretical descriptor and catalytic oxygen reduction activity of graphene supported palladium and palladium alloy electrocatalysts. J. Power Sources 2015, 300, 1-9. [CrossRef]

33. Lüsi, M.; Erikson, H.; Treshchalov, A.; Rähn, M.; Merisalu, M.; Kikas, A.; Kisand, V.; Sammelselg, V.; Tammeveski, K. Oxygen reduction reaction on $\mathrm{Pd}$ nanocatalysts prepared by plasma-assisted synthesis on different carbon nanomaterials. Nanotechnology 2021, 32, 035401. [CrossRef] [PubMed]

34. Liang, Y.; Li, Y.; Wang, H.; Zhou, J.; Wang, J.; Regier, T.; Dai, H. $\mathrm{Co}_{3} \mathrm{O}_{4}$ nanocrystals on graphene as a synergistic catalyst for oxygen reduction reaction. Nat. Mater. 2011, 10, 780-786. [CrossRef] [PubMed]

35. Liang, Y.; Wang, H.; Zhou, J.; Li, Y.; Wang, J.; Regier, T.; Dai, H. Covalent hybrid of spinel manganese-cobalt oxide and graphene as advanced oxygen reduction electrocatalysts. J. Am. Chem. Soc. 2012, 134, 3517-3523. [CrossRef]

36. Osgood, H.; Devaguptapu, S.V.; Xu, H.; Cho, J.; Wu, G. Transition metal (Fe, Co, Ni, and Mn) oxides for oxygen reduction and evolution bifunctional catalysts in alkaline media. Nano Today 2016, 11, 601-625. [CrossRef]

37. Pei, S.; Cheng, H.-M. The reduction of graphene oxide. Carbon 2012, 50, 3210-3228. [CrossRef]

38. Baskakov, S.A.; Manzhos, R.A.; Lobach, A.S.; Baskakova, Y.V.; Kulikov, A.V.; Martynenko, V.M.; Milovich, F.O.; Kumar, Y.; Michtchenko, A.; Kabachkov, E.N.; et al. Properties of a granulated nitrogen-doped graphene oxide aerogel. J. Non-Cryst. Solids 2018, 498, 236-243. [CrossRef]

39. Chen, Z.; Ren, W.; Gao, L.; Liu, B.; Pei, S.; Cheng, H.-M. Three-dimensional flexible and conductive interconnected graphene networks grown by chemical vapour deposition. Nat. Mater. 2011, 10, 424-428. [CrossRef]

40. Li, Y.; Chen, J.; Huang, L.; Li, C.; Hong, J.-D.; Shi, G. Highly compressible macroporous graphene monoliths via an improved hydrothermal process. Adv. Mater. 2014, 26, 4789-4793. [CrossRef]

41. Feng, Y.; Yao, J. Design of Melamine Sponge-Based Three-Dimensional Porous Materials toward Applications. Ind. Eng. Chem. Res. 2018, 57, 7322-7330. [CrossRef]

42. Feng, Y.; Wang, Y.; Wang, Y.; Zhang, X.-F.; Yao, J. In-situ gelation of sodium alginate supported on melamine sponge for efficient removal of copper ions. J. Colloid Interface Sci. 2018, 512, 7-13. [CrossRef] [PubMed]

43. Melamine Sponge. Available online: https://www.melaminefoamtech.com/applications/Melamine-spongeMagiceraserCleaning-Sponge.html (accessed on 7 January 2021).

44. Feng, Y.; Cao, M.; Yang, L.; Zhang, X.-F.; Wang, Y.; Yu, D.; Gu, X.; Yao, J. Bilayer N-doped carbon derived from furfuryl alcohol-wrapped melamine sponge as high-performance supercapacitor. J. Electroanal. Chem. 2018, 823, 633-637. [CrossRef]

45. Ji, C.; Zhang, K.; Li, L.; Chen, X.; Hu, J.; Yan, D.; Xiao, G.; He, X. High performance graphene-based foam fabricated by a facile approach for oil absorption. J. Mater. Chem. A 2017, 5, 11263-11270. [CrossRef]

46. Zhou, J.; Zhang, Y.; Yang, Y.; Chen, Z.; Jia, G.; Zhang, L. Silk fibroin-graphene oxide functionalized melamine sponge for efficient oil absorption and oil/water separation. Appl. Surf. Sci. 2019, 497, 143762. [CrossRef] 
47. Feng, T.; Xu, J.; Yu, C.; Cheng, K.; Wu, Y.; Wang, Y.; Li, F. Graphene oxide wrapped melamine sponge as an efficient and recoverable adsorbent for $\mathrm{Pb}(\mathrm{II})$ removal from fly ash leachate. J. Hazard. Mater. 2019, 367, 26-34. [CrossRef]

48. Song, S.; Yang, H.; Su, C.; Jiang, Z.; Lu, Z. Ultrasonic-microwave assisted synthesis of stable reduced graphene oxide modified melamine foam with superhydrophobicity and high oil adsorption capacities. Chem. Eng. J. 2016, 306, 504-511. [CrossRef]

49. Saha, P.; Dashairya, L. Reduced graphene oxide modified melamine formaldehyde (rGO@ MF) superhydrophobic sponge for efficient oil-water separation. J. Porous Mater. 2018, 25, 1475-1488. [CrossRef]

50. Sun, S.; Tang, S.; Chang, X.; Wang, N.; Wang, D.; Liu, T.; Lei, Y.; Zhu, Y. A bifunctional melamine sponge decorated with silver-reduced graphene oxide nanocomposite for oil-water separation and antibacterial applications. Appl. Surf. Sci. 2019, 473, 1049-1061. [CrossRef]

51. William, S.; Hummers, J.R.; Offeman, R.E. Preparation of Graphitic Oxide. J. Am. Chem. Soc. 1958, 80, 1339.

52. Shulga, Y.M.; Baskakov, S.A.; Smirnov, V.A.; Shulga, N.Y.; Belay, K.G.; Gutsev, G.L. Graphene Oxide Films as Separators of Polyaniline-Based Supercapacitors. J. Power Sources 2014, 245, 33-36. [CrossRef]

53. Baskakov, S.A.; Baskakova, Y.V.; Lyskov, N.V.; Dremova, N.N.; Irzhak, A.V.; Kumar, Y.; Michtchenko, A.; Shulga, Y.M. Fabrication of Current Collector Using a Composite of Polylactic Acid and Carbon Nano-Material for Metal-Free Supercapacitors with Graphene Oxide Separators and Microwave Exfoliated Graphite Oxide Electrodes. Electrochim. Acta 2018, 260, 557-563. [CrossRef]

54. Briggs, D.; Seah, M.P. Practical Surface Analysis by Auger and X-ray Photoelectron Spectroscopy; John Wiley and Sons: Chichester, UK, 1983.

55. Bard, A.J.; Faulkner, L.R. Fundamentals and Applications: Electrochemical Methods, 2nd ed.; Wiley: New York, NY, USA, 2001.

56. Jürmann, G.; Tammeveski, K. Electroreduction of oxygen on multi-walled carbon nanotubes modified highly oriented pyrolytic graphite electrodes in alkaline solution. J. Electroanal. Chem. 2006, 597, 119-126. [CrossRef]

57. Qu, L.T.; Liu, Y.; Baek, J.-B.; Dai, L.M. Nitrogen-doped graphene as efficient metal-free electrocatalyst for oxygen reduction in fuel cells. ACS Nano 2010, 4, 1321-1326. [CrossRef]

58. Shulga, Y.M.; Kabachkov, E.N.; Baskakov, S.A.; Baskakova, Y.V. Doping Graphene Oxide Aerogel with Nitrogen during Reduction with Hydrazine and Low Temperature Annealing in Air. Russ. J. Phys. Chem. A 2019, 93, 296-300. [CrossRef]

59. Komarova, N.S.; Konev, D.V.; Kotkin, A.S.; Kochergin, V.K.; Manzhos, R.A.; Krivenko, A.G. Effect of graphene surface functionalization on the oxygen reduction reaction in alkaline media. Mendeleev Commun. 2020, 30, 472-473. [CrossRef]

60. Meier, R.J.; Maple, J.R.; Hwang, M.-J.; Hagler, A.T. Molecular modeling urea-and melamine-formaldehyde resins. 1. A force field for urea and melamine. J. Phys. Chem. 1995, 99, 5445-5456. [CrossRef]

61. Koglin, E.; Kip, B.J.; Meier, R.J. Adsorption and displacement of melamine at the Ag/electrolyte interface probed by surfaceenhanced Raman microprobe spectroscopy. J. Phys. Chem. 1996, 100, 5078-5089. [CrossRef]

62. He, L.; Liu, Y.; Lin, M.; Awika, J.; Ledoux, D.R.; Li, H.; Mustapha, A. A new approach to measure melamine, cyanuric acid, and melamine cyanurate using surface enhanced Raman spectroscopy coupled with gold nanosubstrates. Sens. Instrum. Food Qual. Saf. 2008, 2, 66-71. [CrossRef]

63. Huang, H.; Shende, C.; Sengupta, A.; Inscore, F.; Brouillette, C.; Smith, W.; Farquharson, S. Surface-enhanced Raman spectra of melamine and other chemicals using a $1550 \mathrm{~nm}$ (retina-safe) laser. J. Raman Spectrosc. 2012, 43, 701-705. [CrossRef]

64. Mircescu, N.E.; Oltean, M.; Chiş, V.; Leopold, N. FTIR, FT-Raman, SERS and DFT study on melamine. Vib. Spectrosc. 2012, 62, 165-171. [CrossRef]

65. Pimenta, M.A.; Dresselhaus, G.; Dresselhaus, M.S.; Cançado, L.G.; Jorio, A.; Saito, R. Studying disorder in graphite-based systems by Raman spectroscopy. Phys. Chem. Chem. Phys. 2007, 9, 1276-1291. [CrossRef] [PubMed]

66. López-Díaz, D.; Holgado, M.L.; García-Fierro, J.L.; Velázquez, M.M. Evolution of the Raman Spectrum with the Chemical Composition of Graphene Oxide. J. Phys. Chem. C 2017, 121, 20489-20497. [CrossRef]

67. Claramunt, S.; Varea, A.; López-Díaz, D.; Velázquez, M.M.; Cornet, A.; Cirera, A. The Importance of Interbands on the Interpretation of the Raman Spectrum of Graphene Oxide. J. Phys. Chem. C 2015, 119, 10123-10129. [CrossRef]

68. Korepanov, V.I. Asymmetric least-squares baseline algorithm with peak screening for automatic processing of the Raman spectra. J. Raman Spectrosc. 2020, 51, 2061-2065. [CrossRef]

69. Korepanov, V.I.; Sedlovets, D.M. An asymmetric fitting function for condensed-phase Raman spectroscopy. Analyst 2018, 143, 2674-2679. [CrossRef]

70. Daems, N.; Sheng, X.; Vankelecom, I.F.J.; Pescarmona, P.P. Metal-free doped carbon materials as electrocatalysts for the oxygen reduction reaction. J. Mater. Chem. A 2014, 2, 4085-4110. [CrossRef]

71. Guo, D.; Shibuya, R.; Akiba, C.; Saji, S.; Kondo, T.; Nakamura, J. Active sites of nitrogen-doped carbon materials for oxygen reduction reaction clarified using model catalysts. Science 2016, 351, 361-365. [CrossRef]

72. Shinagawa, T.; Garcia-Esparza, A.T.; Takanabe, K. Insight on Tafel slopes from a microkinetic analysis of aqueous electrocatalysis for energy conversion. Sci. Rep. 2015, 5, 13801. [CrossRef]

73. Fernandes, D.M.; Mathumba, P.; Fernandes, A.J.S.; Iwuoha, E.I.; Freire, C. Towards efficient oxygen reduction reaction electrocatalysts through graphene doping. Electrochim. Acta 2019, 319, 72-81. [CrossRef]

74. Zhou, Z.; Yan, Q.; Su, F.; Zhao, X.S. Replicating novel carbon nanostructures with 3D macroporous silica template. J. Mater. Chem. 2005, 15, 2569-2574. [CrossRef] 